\title{
A judicialização da saúde: as decisões do Supremo Tribunal Federal frente ao princípio da separação dos poderes
}

\author{
The judicialization of health: the Supreme Court decisions versus the Principle of Check and \\ Balances
}

La judicialización de la salud: las decisiones de la Corte Suprema de Justicia en contra del Principio de la Separación de los Poderes

Resumo: Introdução: A Constituição Federal de 1988, ao qualificar a saúde como um direito fundamental, de acesso universal e igualitário, e dever do Estado, e ao estabelecer a participação do poder judiciário diante de ameaça ou lesão ou aos direitos fez surgir a chamada judicialização da saúde: a interferência desse poder em questões que, primariamente, seriam da competência dos poderes executivos e legislativos. $O$ artigo objetivou identificar o posicionamento do Supremo Tribunal Federal (STF) quanto à interferência do Judiciário diante do princípio da separação dos poderes. Metodologia: Tratou-se de pesquisa qualiquantitativa, de caráter descritivo e analítico, das decisões judiciais proferidas pelo STF, de junho de 2009 a junho de 2015, em sede recursal, de ações cujos objetos pleiteados versavam sobre ações ou serviços de saúde. Resultados e discussão: A análise das decisões demonstra: aumento das demandas de saúde levadas à Suprema Corte em 2014 e 2015; predominância de demandas de assistência farmacêutica e insumos; tendência do Estado de alegar como razões do recurso a violação da separação dos poderes e grave lesão à ordem pública; o entendimento pacificado do STF quanto à matéria. Conclusão: Para o STF a intervenção do Judiciário nas políticas públicas de saúde não fere o princípio da separação dos poderes, nem gera lesão à ordem pública, pois a garantia e efetivação do direito à saúde é responsabilidade do Estado, seja qual for a esfera e a abrangência de suas funções, sendo inadmissível, dentro do modelo constitucional adotado, qualquer dos poderes eximir-se dessa obrigação.

Palavras-chave: Judicialização, Saúde, Direito, Separação, Poderes.

\begin{abstract}
Introduction: The Federal Constitution of de 1988, to qualify the health as a fundamental right, of universal and equal access, and responsibility of the State, and to establish the participation of the judiciary power in the face of threat or injury the rights, emerged the so-called legalization of health: the interference that power on primarily issues be the responsibility of the executive and legislative powers. The article aimed to identify the position of the Supreme Court (STF) and the interference of the judiciary on the separation of powers principle. Methodology: This was qualitative-quantitative research, descriptive and analytical character, of judgments delivered by the Supreme Court, from June 2009 to June 2015, in appeal, the lawsuits about health actions or health services. Results and discussion: The analysis of decisions show: increased health demands brought to the Supreme Court in 2014 and 2015; predominance of pharmaceutical inputs and assistance

\footnotetext{
1 Assessora do Departamento de Planejamento e Regulação da Provisão de Profissionais de Saúde da Secretaria de Gestão do Trabalho e da Educação na Saúde - Ministério da Saúde. Email: tabata08@hotmail.com
} 
demands; trend of the State claimed as appeal reasons the violation of separation of powers and serious injury to the public order; the pacified the understanding of the Supreme Court as the matter. Results and discussion: The analysis of decisions show: increased health demands brought to the Supreme Court in 2014 and 2015; predominance of pharmaceutical inputs and assistance demands; trend of the State claimed as appeal reasons the violation of separation of powers and serious injury to the public order; the pacified the understanding of the Supreme Court as the matter. Conclusion: For the STF, the intervention of the judiciary in public health policy does not violate the principle of separation of powers, does not cause too damage to public order, because the guarantee and realization of the right to health is the State's responsibility, not being allowed, within the constitutional framework adopted, any of the powers disclaim such obligation.

Keywords: Legalization, Health, Law, Separation, Powers.

Resumen: Introducción: La Constitución Federal de 1988, para calificar la salud como un derecho fundamental de acceso universal e igual, y el deber del Estado, y para establecer la participación del poder judicial frente a la amenaza o lesión o los derechos ha dado lugar a la llamada legalización de salud: la interferencia que el poder sea en temas principalmente responsabilidad de los poderes ejecutivo y legislativo. El artículo tiene como objetivo identificar la posición de la Corte Suprema (STF) y la interferencia del poder judicial en el principio de separación de poderes. Metodología: Se realizó una investigación cualitativacuantitativa, de carácter descriptivo y analítico de las sentencias dictadas por el Tribunal Supremo de junio 2009 hasta junio 2015 en las acciones de la sede de recurso cuyos objetos fueron declarado acerca de acciones o servicios de salud. Resultados y discusión: El análisis de las decisiones Mostrar: aumento de las demandas de salud llevados a la Corte Suprema en 2014 y 2015; predominio de las demandas de insumos farmacéuticos y asistencia; Estado de la tendencia reivindica como una característica de las razones por violación de la separación de poderes y el daño grave al orden público; pacificado la comprensión de la Corte Suprema como la materia. Conclusión: Para la intervención STF del poder judicial en la política de salud pública no viola el principio de separación de poderes, o resulta dañado por el orden público, ya que la garantía y el ejercicio del derecho a la salud es responsabilidad del Estado, cualquiera que sea la pelota y el ámbito de sus funciones, siendo inadmisible, dentro del marco constitucional aprobada, ninguno de los poderes renuncia a dicha obligación.

Palabras-Ilave: Legalización, Salud, Derecho, Separación, Powers.

\section{Introdução}

A partir da Constituição Federal de 1988 (1) a saúde deixou de ser um direito assegurado apenas aos trabalhadores inseridos formalmente no mercado de trabalho, para passar a ser um direito fundamental, de acesso universal e igualitário, de natureza social (art. 6º, CF/88), e de relevância pública em um Estado democrático de direito, baseado na defesa dos direitos fundamentais e na realização da justiça social (1). 
Dallari e Nunes Júnior (2) afirmam que a saúde, vista dentro do ordenamento constitucional como uma condição essencial à dignidade da pessoa humana, é um direito de prestação pública, que se materializa por meio de serviços e ações do Estado.

O legislador constitucional, diante da necessidade de uma atuação positiva do Estado, atribuiu ao Poder Público o dever, não só de garantir o acesso aos serviços e ações de saúde por meio de políticas públicas que visem à promoção, proteção e recuperação da saúde, deu-lhe também a tarefa de normatização, fiscalização e controle das ações de saúde, tanto no âmbito público, como no âmbito privado (3).

A Constituição Federal ao assegurar diversas garantias constitucionais, com o objetivo de dar maior efetividade aos direitos fundamentais, em especial o acesso universal integral e igualitário à saúde, estabeleceu a participação do poder judiciário diante de ameaça ou lesão ou aos direitos.

Diante dessa atribuição conferida ao Judiciário, tornou-se cada vez mais frequente a interferência desse poder em questões que, primariamente, seriam da competência dos poderes executivos ou legislativos. É a partir desse papel desempenhado pelo poder judiciário na garantia de direitos fundamentais que surgi a judicialização.

Segundo Barroso (4), a judicialização pode ser compreendida da seguinte forma:

Judicialização significa que algumas questões de larga repercussão política ou social estão sendo decididas por órgãos do Poder Judiciário, e não pelas instâncias políticas tradicionais: o Congresso Nacional e o Poder Executivo em cujo âmbito se encontram o Presidente da República, seus ministérios e a administração pública em geral. Com o intuitivo, a judicialização envolve uma transferência de poder para juízes e tribunais, com alterações significativas na linguagem, na argumentação e no modo de participação da sociedade.

No âmbito da saúde, a judicialização se consolidou como resposta a um contexto marcado pela exclusão no acesso aos serviços de saúde (5) e morosidade dos poderes executivo e legislativo em satisfazerem de forma efetiva as demandas acerca do acesso às ações e serviços de saúde.

Diante da intervenção do Judiciário em questões tipicamente inseridas no campo de competência dos demais poderes, surge o debate acerca da legalidade dessa ingerência, haja vista a garantia constitucional da independência e da harmonia entre os três poderes do Estado brasileiro (1). 
A Teoria Clássica da Separação dos Poderes do Estado, abordada por Montesquieu no Livro XI da obra Do Espírito das Leis, lecionava que a liberdade política dos governos moderados, seria encontrada quando nesses não houvesse abuso de poder, sendo necessário para tanto que um poder viesse a ser um freio para o outro. Tal controle entre os poderes só poderia ser posto em prática por meio de disposições constitucionais que atribuíssem a órgãos distintos as três funções do Estado (4).

Capano (7), ao fazer uma leitura contemporânea da teoria da separação dos poderes, afirma que:

\begin{abstract}
Embora o pensamento de Locke seja reconhecido como o antecedente mais próximo da teoria da separação dos poderes, é com Montesquieu que a doutrina adquire sua forma mais clássica. Em apenas poucas linhas e com bastante lucidez, o pensador sintetiza o propósito essencial da teoria da separação dos poderes: "A liberdade política só se encontra nos Governos moderados. Mas ela não existe sempre nos Estados moderados. Ela só existe neles quando não se abusa do poder. Mas é uma experiência eterna que todo o homem que tem poder é levado a abusar dele. Vai até encontrar limites. Quem diria! A própria virtude precisa de limites. Para que não possam abusar do poder, precisa que, pela disposição das coisas, o poder freie o poder.
\end{abstract}

Com a evolução dos modelos de Estado e a necessidade de aliar a democracia da tradicional separação dos poderes às novas realidades sócio-políticas que se apresentavam surgiu a necessidade de adequação da Teoria Clássica ao bom desempenho das atividades do Estado. Os poderes estatais deixaram de ser vistos como efetivamente separados e rigidamente especializados, para serem interpretados como distintos e coordenados (7).

Foram nas Constituições democráticas que nasceu a ideia de colaboração entre os poderes do Estado (8), na qual cada poder permanecia com a sua autonomia organizacional, mas com a possibilidade de intercomunicação de funções, exercidas sistematicamente em cooperação mútua. Surgia-se assim a nova divisão dos poderes, baseada na independência orgânica e da harmonia entre legislativo, executivo e judiciário.

Quando à independência e harmonia entre os poderes, Silva (9) assevera que "a harmonia entre os poderes verifica-se primeiramente pelas normas de cortesia no trato recíproco e no respeito às prerrogativas e faculdades a que mutuamente todos têm direito", todavia cumpre observar que a independência, assim como as funções não são de caráter absoluto, pois são passíveis de interferências que objetivam manter o "equilíbrio necessário 
à realização do bem da coletividade e indispensável para evitar o arbítrio e o demando de um em detrimento do outro [...]".

Diante do modelo constitucional brasileiro, Silva (8) elucida que independência e a divisão de funções entre os poderes não são absolutas, pois além do respeito às prerrogativas de cada poder, a harmonia pressupõe interferências funcionais:

Tudo isso demonstra que os trabalhos do Legislativo e do Executivo, especialmente, mas também do Judiciário, só se desenvolverão a bom termo, se esses órgãos se subordinarem ao princípio da harmonia, que não significa nem o domínio de um pelo outro nem a usurpação de atribuições, mas a verificação de que, entre eles, há de haver consciente colaboração e controle recíproco (que, aliás, integra o mecanismo), para evitar distorções e desmandos.

Assim, a visão contemporânea da separação dos poderes estabelece que cada função governamental é exercida preponderantemente por um órgão específico, entretanto, essa repartição de atribuições para cada órgão não é absoluta.

Os poderes encontram prerrogativas constitucionais para participar das atribuições uns dos outros, desempenhando funções atípicas, a fim de que garantir a atuação eficiente e eficaz do Estado. No entanto, essas funções atípicas são secundárias ou subsidiárias, devendo ser exercidas nos limites do texto constitucional, visando a manutenção do equilíbrio entre os poderes (8).

Partindo dessa discussão, o estudo proposto objetiva identificar, por meio da análise jurisprudencial, como o Supremo Tribunal Federal - STF, na qualidade de guardião da Lei Fundamental ${ }^{2}$, posiciona-se quanto à judicialização da saúde frente ao princípio da separação dos poderes previsto no texto constitucional.

\section{Metodologia}

Este artigo adotou como método a pesquisa qualiquantitativa, de caráter descritivo e analítico, das decisões judiciais proferidas pelo Supremo Tribunal Federal (STF), em sede recursal, de ações de conhecimento ajuizadas na primeira instância das justiças estaduais e justiça federal, cujos objetos pleiteados tratavam da assistência farmacêutica e insumos;

\footnotetext{
2 "[...] A interpretação constitucional derivada das decisões proferidas pelo STF - a quem se atribuiu a função eminente de 'guarda da Constituição' (CF, art. 102, caput) - assume papel de essencial importância na organização institucional do Estado brasileiro, a justificar o reconhecimento de que o modelo político-jurídico vigente em nosso País confere, à Suprema Corte, a singular prerrogativa de dispor do monopólio da última palavra em tema de exegese das normas inscritas no texto da Lei Fundamental" (9).
} 
assistência médico-hospitalar; e qualidade dos serviços de saúde pública ofertados/implantação de política pública.

As amostras da pesquisa foram colhidas no banco de dados de decisão sítio da Suprema Corte, por meio das ferramentas de busca e consulta disponível para pesquisa de jurisprudência (acórdãos), com a utilização dos descritores: direito; saúde; e separação dos poderes, com o recorte temporal de junho de $2009^{3}$ a junho de 2015.

Foram encontrados 25 acórdãos com o tema da saúde. Após a leitura das decisões, foram descartados da amostra 10 acórdãos cujas ações originárias de conhecimento não tratavam do objeto deste estudo.

Para a análise das 15 amostras foram aplicados procedimentos sistemáticos e objetivos para a descrição do conteúdo das amostras, com a finalidade de compreensão e avaliação das informações contidas no material de pesquisa.

A título de complementação do aporte teórico, foi realizada a revisão bibliográfica da literatura sobre os principais conceitos que circundam o tema do direito à saúde e a judicialização desse direito.

Para isso, foram consultados livros, artigos científicos, teses e dissertações elaboradas e publicadas por pesquisadores e militantes do direito sanitário, nas bases de dados do Scielo e Google acadêmico, predominantemente nos anos de 2009 a 2015, tendo por critérios de triagem: literaturas de acesso livre e publicadas em língua portuguesa, com conteúdo acerca dos princípios, direitos e garantias fundamentais, relativo aos ideais e ao modelo de Estado adotado pela CF/88, expostos nos Título I, II e VIII do texto constitucional; e da judicialização da política e, em específico, a da saúde, que abordam as implicações desse fenômeno na ordem política-adminstrativa e social do Brasil.

\section{Resultados e discussão}

A pesquisa demonstrou que apesar da Audiência Pública sobre a judicialização da saúde ter ocorrido em 2009, somente a partir de 2010, que os ministros da Suprema Corte iniciaram os julgamentos dos recursos das demandas que pleiteavam, em desfavor do Estado, ações e serviços de saúde.

${ }^{3}$ O marco inicial do recorte temporal de junho de 2009 foi adotado em razão da Audiência Pública no 4, que ocorreu em 27, 28 e 29 de abril e em 4,6 e 7 de maio de 2009, convocada pelo ministro Gilmar Mendes, presidente do STF à época, com o tema da judicialização da saúde no âmbito do Sistema Único de Saúde (SUS). 
Tabela 1. Classificação quantitativa da distribuição e julgamento das demandas pelo STF.

\begin{tabular}{l|c|c|c|c|c|c|c|c|c}
\hline \multirow{2}{*}{ Órgão julgador - STF } & \multicolumn{7}{c|}{ Ano de julgamento } & \multirow{2}{*}{ Total } & \multirow{2}{*}{$(\%)$} \\
\cline { 2 - 11 } & 2009 & 2010 & 2011 & 2012 & 2013 & 2014 & 2015 & Geral & \\
\hline Primeira Turma & - & - & - & 1 & 2 & 3 & 3 & 9 & 60 \\
\hline Segunda Turma & - & - & - & - & - & 2 & 2 & 4 & 27 \\
\hline Tribunal Pleno & - & 2 & - & - & - & - & - & 2 & 13 \\
\hline \multicolumn{1}{c}{ Total } & - & 2 & - & 1 & 2 & 5 & 5 & 15 & 100 \\
\hline
\end{tabular}

Fonte: Produzida pela autora com base em análise da jurisprudência do Supremo Tribunal Federal (10).

De acordo com os dados obtidos, foi observado que foi a partir de 2014 que a demanda de julgamentos pela Suprema Corte aumentou, representando um aumento da tendência de transferir ao poder judiciário o papel de garantir o acesso e a efetivação do direito à saúde, que constitucionalmente é função típica dos poderes executivos e legislativos, por meio da implementação de políticas públicas.

Quanto ao objeto pleiteado nas ações de conhecimento, foi verificado que $20 \%$ das amostras trataram da qualidade dos serviços de saúde pública ofertados/implantação de política pública, enquanto que 33\% cuidaram da assistência médico-hospitalar. Já a maior parte das amostras, 47\%, versou sobre a assistência farmacêutica e insumos, conforme demonstrado na tabela 2:

Tabela 2. Classificação quanto ao objeto pleiteado nas demandas.

\begin{tabular}{l|c|c|c|c|c|c|c|c|c}
\hline \multirow{1}{*}{ Tipo de prestação } & \multicolumn{7}{c|}{ Ano de julgamento } & Total & (\%) \\
\cline { 2 - 10 } & 2009 & 2010 & 2011 & 2012 & 2013 & 2014 & 2015 & Geral & \\
\hline $\begin{array}{l}\text { Assistência farmacêutica e } \\
\text { insumos }\end{array}$ & - & 1 & - & - & 1 & 3 & 2 & 7 & 47 \\
\hline $\begin{array}{l}\text { Assistência médico- } \\
\text { hospitalar }\end{array}$ & - & - & - & - & - & 2 & 3 & 5 & 33 \\
\hline $\begin{array}{l}\text { Qualidade dos serviços de } \\
\text { saúde pública } \\
\text { ofertados/implantação de } \\
\text { política pública }\end{array}$ & - & 1 & - & 1 & 1 & - & - & 3 & 20 \\
\hline \multicolumn{1}{c}{ Total } & - & 2 & - & 1 & 2 & 5 & 5 & 15 & 100 \\
\hline
\end{tabular}

Fonte: Produzida pela autora com base em análise da jurisprudência do Supremo Tribunal Federal (10).

Ao analisar os dados obtidos quando as amostras foram classificadas e analisadas pelo objeto da ação originária, percebeu-se que inicialmente, pelo menos nos 3 primeiros 
anos (2010-2012-2013) em que exerceu o papel de garantir o direito à saúde, o STF interviu diretamente nas políticas públicas de saúde, seja na qualidade dos serviços prestados, seja na necessidade/obrigação da implantação da política.

Já em 2014 e 2015, a intervenção da Suprema Corte teve o foco alterado para a garantia da assistência farmacêutica/insumos e da assistência médico-hospitalar. Observase que a intervenção da última instância do poder judiciário não foi motivada pela ausência de ação ou pela morosidade dos demais poderes quanto ao acesso adequado à saúde, mas sim na universalidade e equidade desse acesso.

O poder público ao se tornar o responsável por tais garantias, seja qual for a sua esfera de atuação (municipal/distrital, estadual e federal) não pode apenas implantar as ações e disponibilizar os serviços e insumos, deve ser garantido também o acesso amplo, irrestrito e indiscriminado a todos os meios que possam a assegurar a saúde (redução do agravo/recuperação) do indivíduo.

Como dito anteriormente, todas as amostras estudadas trataram de ações originárias ajuizadas contra o Estado (União, Estados e Municípios), que diante dos julgamentos desfavoráveis das instâncias inferiores, apresentou, no Supremo Tribunal, recurso almejando a reforma das decisões, sob o fundamento da ocorrência grave lesão à ordem, à economia, à saúde e à segurança públicas e a violação do princípio da separação dos poderes.

Os quadros 1, 2 e 3, sistematizam, por tipo de demanda, os recorrentes e as decisões do STF quanto à cada amostra analisada. 
Quadro 1. Classificação das demandas de assistência farmacêutica e insumos quanto ao recorrente e a decisão do STF.

\begin{tabular}{|c|c|c|}
\hline \multicolumn{3}{|c|}{ Demandas de assistência farmacêutica e insumos } \\
\hline № Processo & Recorrente & Acórdão (resumo da ementa) \\
\hline $\begin{array}{l}1 \text { STA - Agr } \\
175 \text { / CE }\end{array}$ & União & $\begin{array}{l}\text { Políticas públicas. Responsabilidade solidária dos entes da } \\
\text { Federação em matéria de saúde. Não comprovação de grave } \\
\text { lesão à ordem, à economia, à saúde e à segurança pública. } \\
\text { Possibilidade de ocorrência de dano inverso. Agravo } \\
\text { regimental a que se nega provimento. }\end{array}$ \\
\hline 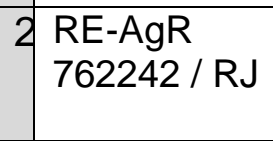 & $\begin{array}{l}\text { Estado do } \\
\text { Rio de } \\
\text { Janeiro }\end{array}$ & $\begin{array}{l}\text { Direito à saúde. Dever do Estado. Violação do princípio da } \\
\text { separação dos poderes. Não ocorrência. Precedentes. Agravo } \\
\text { regimental conhecido e não provido. }\end{array}$ \\
\hline $\begin{array}{l}3 \text { RE } 429903 / \\
\text { RJ }\end{array}$ & $\begin{array}{l}\text { Estado do } \\
\text { Rio de } \\
\text { Janeiro }\end{array}$ & $\begin{array}{l}\text { Fornecimento de medicamento e manutenção em estoque. } \\
\text { Ausência de ofensa ao princípio da separação dos poderes. } \\
\text { Constitucional. Direito à saúde. Dever. Poder público. Recurso } \\
\text { extraordiário a que se nega provimento. }\end{array}$ \\
\hline 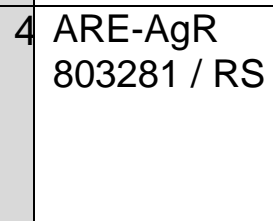 & $\begin{array}{l}\text { Estado do } \\
\text { Rio Grande } \\
\text { do Sul }\end{array}$ & $\begin{array}{l}\text { Direito à saúde. Responsabilidade solidária dos entes da } \\
\text { federação. Ofensa ao princípio da separação de poderes. } \\
\text { Inocorrência. Atribuição de fornecimento de fármaco para } \\
\text { tratamento oncológico. Agravo regimental a que se nega } \\
\text { provimento. }\end{array}$ \\
\hline 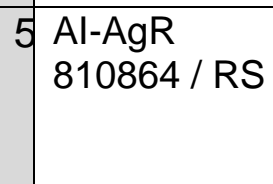 & $\begin{array}{l}\text { Estado do } \\
\text { Rio Grande } \\
\text { do Sul }\end{array}$ & $\begin{array}{l}\text { Direito à saúde. Fornecimento pelo poder público de fraldas } \\
\text { descartáveis. Inexistência de ofensa ao princípio da } \\
\text { separação dos poderes. Solidariedade dos entes federativos. } \\
\text { Agravo regimental a que se nega provimento. }\end{array}$ \\
\hline $\begin{array}{l}6 \text { ARE-AgR } \\
859350 / \\
\text { SC }\end{array}$ & União & $\begin{array}{l}\text { Direito à saúde. Fornecimento de medicamentos. Ofensa ao } \\
\text { princípio da separação dos poderes. Inocorrência. } \\
\text { Responsabilidade solidária entre os entes federados. Agravo } \\
\text { regimental a que se nega provimento. }\end{array}$ \\
\hline $\begin{array}{l}7 \text { ARE-AgR } \\
892114 / \\
\text { MG }\end{array}$ & $\begin{array}{l}\text { Município de } \\
\text { Uberaba/MG }\end{array}$ & $\begin{array}{l}\text { Direito à saúde. Tratamento médico. Responsabilidade } \\
\text { solidária dos entes federados. Inexistência de ofensa ao } \\
\text { princípio da separação dos poderes. Agravo regimental } \\
\text { conhecido e não provido. }\end{array}$ \\
\hline
\end{tabular}

Fonte: Produzido pela autora com base em análise da jurisprudência do Supremo Tribunal Federal (10).

Das 7 amostras que trataram das demandas de assistência farmacêutica e insumos, percebeu-se que: 4 delas chegaram ao STF para julgamento de recursos interpostos pelos Estados da Federação; 2 por recurso interposto pela União; e 1 por recurso apresentado por Município.

Da análise das amostras, observou-se que 100\% dos recursos apresentados tiveram o provimento negado, sendo mantida a decisão condenatória, pois os ministros da Suprema Corte entenderam pela não inocorrência de violação ao princípio do princípio da separação dos poderes e pela existência da responsabilidade solidária entre os entes da Federação 
quanto à garantia da assistência farmacêutica e insumos para a efetivação do direito à saúde.

Quadro 2. Classificação das demandas de qualidade dos serviços de saúde pública ofertados/implantação de política pública quanto ao recorrente e a decisão do STF.

\begin{tabular}{|l|l|l|l|}
\hline \multicolumn{2}{|c|}{ Demandas de qualidade dos serviços de saúde pública ofertados/implantação de política pública } \\
\hline & No Processo & Recorrente & \multicolumn{1}{c|}{ Acórdão (resumo da ementa) } \\
\hline 1 & $\begin{array}{l}\text { SL-AgR } 47 \\
\text { / PE }\end{array}$ & $\begin{array}{l}\text { Estado de } \\
\text { Pernambuco }\end{array}$ & $\begin{array}{l}\text { Políticas públicas. Ordem de regularização dos serviços } \\
\text { prestados em hospital público. Não comprovação de grave lesão } \\
\text { à ordem, à economia, à saúde e à segurança pública. } \\
\text { Possibilidade de ocorrência de dano inverso. Agravo regimental } \\
\text { a que se nega provimento. }\end{array}$ \\
\hline 2 & $\begin{array}{l}\text { Al-AgR } \\
809018 / \\
\text { SC }\end{array}$ & $\begin{array}{l}\text { Estado de } \\
\text { Santa } \\
\text { Catarina }\end{array}$ & $\begin{array}{l}\text { Implementação de políticas públicas. Possibilidade. Violação do } \\
\text { princípio da separação dos poderes. Não ocorrência. Agravo } \\
\text { regimental não provido. }\end{array}$ \\
\hline 3 & $\begin{array}{l}\text { RE-AgR } \\
642536 / \\
\text { AP }\end{array}$ & $\begin{array}{l}\text { Estado do } \\
\text { Amapá }\end{array}$ & $\begin{array}{l}\text { Sistema público de saúde local. Poder judiciário. Determinação } \\
\text { de adoção de medidas para a melhoria do sistema. } \\
\text { Possibilidade. Princípios da separação dos poderes e da reserva } \\
\text { do possível. Violação. Inocorrência. Agravo regimental a que se } \\
\text { nega provimento. }\end{array}$ \\
\hline
\end{tabular}

Fonte: Produzido pela autora com base em análise da jurisprudência do Supremo Tribunal Federal (10).

Quanto aos recursos interpostos contras as decisões que visaram à garantia da qualidade dos serviços de saúde pública ofertados/implantação de política pública (quadro 2), o STF não identificou a ocorrência de violação ou grave lesão à ordem, à economia, à saúde e à segurança pública que justificassem a reforma da decisão que condenou os Estados de Pernambuco, Santa Catarina e Amapá de adorem as medidas necessárias para a implementação de políticas públicas, regularização e melhoria das ações e serviços de saúde. 
Quadro 3. Classificação das demandas de assistência médico-hospitalar quanto ao recorrente e a decisão do STF.

\begin{tabular}{|c|c|c|c|}
\hline \multicolumn{4}{|c|}{ Demandas de assistência médico-hospitalar } \\
\hline & $\begin{array}{l}\text { Número do } \\
\text { Processo }\end{array}$ & Recorrente & Acórdão (resumo da ementa) \\
\hline 1 & $\begin{array}{l}\text { ARE-AgR } \\
801676 / \\
\text { PE }\end{array}$ & $\begin{array}{l}\text { Estado de } \\
\text { Pernambuco }\end{array}$ & $\begin{array}{l}\text { Direito à saúde. Fornecimento pelo poder público do tratamento } \\
\text { adequado. Solidariedade dos entes federativos. Ofensa ao } \\
\text { princípio da separação dos poderes. Não ocorrência. } \\
\text { Prevalência do direito à vida. Agravo regimental a que se nega } \\
\text { provimento. }\end{array}$ \\
\hline 2 & $\begin{array}{l}\text { RE-AgR } \\
820910 / \\
\text { CE }\end{array}$ & União & $\begin{array}{l}\text { Direito à saúde. Realização de tratamento médico. Obrigação } \\
\text { solidária dos entes da federação. Situação de omissão da } \\
\text { administração pública. Concretização de políticas públicas pelo } \\
\text { poder judiciário. Possibilidade. Agravo a que se nega } \\
\text { provimento. }\end{array}$ \\
\hline 3 & $\begin{array}{l}\text { ARE-AgR } \\
814878 / \\
\text { PE }\end{array}$ & União & $\begin{array}{l}\text { Direito à saúde. Determinação de fornecimento de tratamento } \\
\text { médico. Ofensa ao princípio da separação dos poderes. } \\
\text { Inocorrência. Responsabilidade solidária dos entes federados. } \\
\text { Agravo regimental a que se nega provimento. }\end{array}$ \\
\hline 4 & \begin{tabular}{|l} 
ARE-AgR \\
879204 / RJ
\end{tabular} & $\begin{array}{l}\text { Estado do } \\
\text { Rio de } \\
\text { Janeiro }\end{array}$ & $\begin{array}{l}\text { Direito à saúde. Implementação de políticas públicas. } \\
\text { Inexistência de ofensa ao princípio da separação dos poderes. } \\
\text { Consonância da decisão recorrida com a jurisprudência } \\
\text { cristalizada no Supremo Tribunal Federal. Agravo regimental } \\
\text { conhecido e não provido. }\end{array}$ \\
\hline 5 & $\begin{array}{l}\text { RE-AgR } \\
696077 / \\
\text { RS }\end{array}$ & $\begin{array}{l}\text { Estado do } \\
\text { Rio Grande } \\
\text { do Sul }\end{array}$ & $\begin{array}{l}\text { Direito à saúde. Implementação de políticas públicas. } \\
\text { Inexistência de ofensa ao princípio da separação dos poderes. } \\
\text { Agravo regimental conhecido e não provido. }\end{array}$ \\
\hline
\end{tabular}

Fonte: Produzido pela autora com base em análise da jurisprudência do Supremo Tribunal Federal (10).

Nas amostras que trataram da assistência médico-hospitalar, na qual figuraram com recorrentes a União (em duas 2 demandas) e os Estados (em 3), o não provimento dos recursos apresentados pelos entes da Federação foi unânime, visto que prevaleceu o entendimento cristalizado do STF quanto à inexistência de ofensa ao princípio da separação dos poderes quando se trata de ações de pleiteiam a concessão de assistência médicohospitalar, diante da ineficácia ou omissão do poder público em garantir o acesso integral e irrestrito de todos os meios necessários para a redução de risco do agravo, para a recuperação, proteção e promoção da saúde.

\section{Considerações finais}

Segundo Santos (11), a judicialização da política é percebida quando os órgãos integrantes do poder judiciário interferem expressivamente na ação política, no âmbito da 
execução das funções típicas de outro poder, isto é, aquelas que, diante de sua natureza, são de maior preponderância, inerentes e intrínsecas a determinado Poder. Quando o poder estatal ultrapassa a barreira das funções que originariamente não the foram atribuídas, verifica-se o exercício atípico da função.

Diante dessa leitura, entende-se que, em um Estado democrático de direito, para que as liberdades individuais sejam garantidas, a repartição das atividades públicas é condição indispensável para evitar a concentração demasiada das funções em um mesmo ente (4).

Assim, sendo o direito à saúde um dever do Estado, de relevância pública, devendo ser efetivado por meios de ações e de políticas públicas, não deve ser visto apenas como responsabilidade exclusiva de um único poder (detentor e controlador do aparelho público). A garantia e efetividade do direito à saúde extrapolam os limites de atuação do poder executivo, sendo de responsabilidade do Estado, seja qual for a esfera e a abrangência de suas funções, sendo inadmissível, dentro do modelo constitucional adotado, qualquer dos poderes eximir-se dessa obrigação (9), não configurando o "exercício deliberado da vontade política" pelo Poder Judiciário (12).

Observa-se que o poder judiciário, quando evocado para satisfazer uma prestação legalmente prevista, interfere nas políticas públicas de saúde, de competência típica dos poderes executivo e legislativo, por meio do exercício de suas funções atípicas, coloca-se como via de acesso e efetivação do direito à saúde, provocando atualmente, no âmbito da judicialização da saúde, aumento significativo de ações judiciais ajuizadas com esse intuito.

O Estado quando instado pelas decisões judiciais a cumprir com a sua função típica, dentro do contexto do direito à saúde, alega, muitas vezes, em sede de defesa ou como fundamento recursal, a violação do princípio da separação dos poderes pelo Judiciário, que adentra no campo de competência do poder executivo, ao se posicionar quanto à conveniência, oportunidade e finalidade do mérito administrativo inerente às ações e aos serviços públicos de saúde.

A interferência do Judiciário, no âmbito da função típica do Executivo e Legislativo, se justifica como meio de assegurar aos cidadãos a garantia e efetividade dos direitos quando violados pela leniência, inércia ou incapacidade dos poderes detentores da função típica.

A "incapacidade de o Executivo e o Legislativo fornecerem respostas efetivas à explosão das demandas sociais por justiça" (13), diante dos ideais democráticos instituídos 
pela Constituição Federal de 1988, fez com que a concretização dos direitos nela previstos, recaísse sob o poder judiciário.

Deste modo verifica-se que o poder judiciário ao intervir nos atos administrativos dos demais Poderes, quando provocado, determinando que os demais Poderes adotem medidas cuja finalidade seja a viabilização da satisfação de direitos constitucionalmente previstos, não está inovando na ordem jurídica, nem intervindo no mérito administrativo e discricionário do Poder Executivo, mas sim determinando que tal Poder obedeça às políticas públicas já instituídas.

Desta forma, tem-se que o Poder Judiciário ao intervir nas políticas públicas de saúde, não está ferindo o princípio da separação dos poderes, adentrando na esfera de análise do mérito administrativo, ou interferindo na discricionariedade da Administração Pública, mas está na verdade garantindo ao sujeito de direitos que busque a concretização de um direito fundamental, que necessita da atuação eficaz do Estado para que se efetive, não configurando, "exercício deliberado da vontade política" (12) pelo Poder Judiciário.

Seguindo nessa direção, a Suprema Corte pacificou o entendimento de que o poder judiciário tem legitimidade para determinar que os demais poderes tomem as providências concretas, a fim de garantir a efetivação de direitos constitucionalmente reconhecidos como essenciais, como é o caso do direito à saúde, sem, contudo configurar violação do princípio da separação dos poderes, previsto no art. $2^{\circ}$, da CF/88.

\section{Referências}

1. Brasil. Constituição da República Federativa do Brasil, 5 de outubro de 1988 [Internet]. Brasília, 1988 [Acesso em 6 out 2015]. Disponível em: http://www.planalto.gov.br/ccivil_03/Constituicao/ConstituicaoCompilado.htm

2. Dallari SG, Nunes Júnior VS. Direito Sanitário. São Paulo: Verbatim; 2010.

3. Canotilho JJG. Direito Constitucional e Teoria da Constituição. 7. ed. Coimbra: Almedina; 2012.

4. Barroso LR. Judicialização, ativismo judicial e legitimidade democrática. Brasília. [Acesso 15 set 2015]. Disponível em http://www.cnj.jus.br/eadcnj/mod/resource/view.php?id=47743

5. Sant'ana RN. A saúde aos cuidados do judiciário: a judicialização das políticas de assistência farmacêutica no Distrito Federal a partir da jurisprudência do TJDFT. 
[Dissertação]. Brasília: Mestrado em Direito, Universidade de Brasília; 2009. [Acesso em 15 set 2015]. Disponível em http://repositorio.unb.br/handle/10482/4153

6. Barbosa MC. Revisão da Teoria da Separação dos Poderes do Estado. Revista Científica da Faculdade Lourenço Filho.2006, 5 (1): 1-16. [Acesso em 20 set 2015]. Disponível em http://www.flf.edu.br/revista-flf.edu/volume05/v5mono4.pdf

7. Capano FF. A leitura contemporânea da teoria da separação de poderes: desafio para a melhor efetivação das políticas públicas concretizadoras da Constituição. In: Smanio GP, Bertolini PTM. O direito e as políticas públicas no Brasil. São Paulo: Atlas; 2013, p. 63-82.

8. Silva, JA. Curso de Direito Constitucional Positivo. 38. ed. São Paulo: Malheiros; 2015.

9. Supremo Tribunal Federal. A Constituição e o Supremo. Brasília. [Acesso 15 set 2015]. Disponível em http://www.stf.jus.br/portal/constituicao/artigoBD.asp?item=1093

10. Supremo Tribunal Federal. Busca na jurisprudência. Brasília. [Acesso 31 out 2015]. Disponível em: http://www.stf.jus.br/portal/jurisprudencia/listarConsolidada.asp

11. Santos BS. A judicialização da Política. Lisboa, Centro de Excelência - Processo de Avaliação de Unidades de Investigação do Ministério da Ciência e da Tecnologia - CES Centro de Estudos Sociais; 2003. [Acesso em 15 set 2015]. Disponível em: https://www.ces.uc.pt/opiniao/bss/078.php

12. Barroso LR. O Direito Constitucional e a Efetividade de Suas Normas. Limites e possibilidades da Constituição Brasileira. 9. ed. Rio de Janeiro: Renovar; 2009.

13. Melo MPC, Vianna LW, Carvalho MAR. A judicialização da política e das relações sociais no Brasil. 2. ed. Rio de Janeiro: Revan; 1999.

Recebido em: 13.1.2016

Reapresentado em: 10.10.2016

Aprovado em: 23.1.2017

\section{Como citar este artigo:}

Costa TS. A judicialização da saúde: as decisões do Supremo Tribunal Federal frente ao princípio da separação dos poderes. Revista Cadernos Ibero-Americanos de Direito Sanitário. 2017 jan./mar, 6(1):139-152. 